\title{
Alpha-2-antiplasmin Arg407Lys polymorphism and cryptogenic ischemic cerebrovascular events: Association with neurological deficit
}

\author{
Joanna Wzorek ${ }^{a}$, Marek Karpiński $^{a}$, Ewa Wypasek ${ }^{a, b}$, Michał Michalski $^{a}$, \\ Andrzej Szczudlik ${ }^{a}$, Krzysztof Piotr Malinowski ${ }^{c}$, Anetta Undas ${ }^{a, b, *}$ \\ a John Paul II Hospital, Cracow, Poland \\ ${ }^{\mathrm{b}}$ Institute of Cardiology, Jagiellonian University School of Medicine, Cracow, Poland \\ ${ }^{\mathrm{c}}$ Institute of Public Health, Faculty of Health Science, Jagiellonian University Medical College, Cracow, Poland
}

\section{A R T I C L E I N F O}

Article history:

Received 9 November 2017

Accepted 19 December 2017

Available online 26 December 2017

\section{Keywords:}

$\alpha$-2-Antiplasmin

Arg407Lys polymorphism

Ischemic stroke

Transient ischemic attack

\begin{abstract}
A B S T R A C T
Objective: Genetic background of cryptogenic ischemic stroke (IS) and transient ischemic attack (TIA) remains uncertain. Alpha-2-antiplasmin ( $\alpha 2 \mathrm{AP}$ ) Arg407Lys polymorphism has been shown to be less common in patients with abdominal aortic aneurysm (AAA) compared with healthy controls. We investigated associations of $\alpha 2$ AP Arg407Lys polymorphism with cryptogenic IS and TIA.

Methods: We studied 165 consecutive Caucasian patients who experienced cryptogenic IS $(n=123)$ or TIA $(n=42)$. Neurological outcomes were assessed using the modified Rankin Scale (mRS) in the acute phase of cerebral ischemia and 8 (6-12) months after the index episode. Patients were genotyped for $\alpha 2$ AP Arg407Lys polymorphism (rs1057335) using real time PCR technique.

Results: The allele frequency of Arg407Lys polymorphism was: 0.82/0.18. The 407Lys allele was more frequent in TIA patients compared to the IS group (0.29 vs. $0.14, p=0.003$ ). In the whole group, as well as in IS and TIA patients analyzed separately, possession of the 407Lys allele was associated with excellent outcome (mRS 0-1) during follow-up $(p<0.05)$ but not in the acute phase of ischemic events both in thrombolyzed and nonthrombolyzed Is patients.

The multivariate logistic regression model showed that the excellent outcome (mRS 0-1) assessed after 8 (6-12) months since the index cerebral ischemia was predicted by the occurrence of Lys407 allele (OR 6.18, 95\% CI, 2.01-18.98, $p=0.001$ ).

Conclusion: The presence of 407Lys allele is associated with better prognosis in cryptogenic cerebrovascular events. Our findings suggest that the $\alpha 2$ AP Arg407Lys polymorphism could be involved in the pathogenesis of cerebral ischemia and its outcomes.
\end{abstract}

( 2017 Published by Elsevier Sp. z o.o. on behalf of Polish Neurological Society.

\footnotetext{
* Corresponding author at: Institute of Cardiology, Jagiellonian University School of Medicine, 80 Pradnicka St., 31-202 Cracow, Poland.

E-mail address: mmundas@cyf-kr.edu.pl (A. Undas).

https://doi.org/10.1016/j.pjnns.2017.12.009

0028-3843/@ 2017 Published by Elsevier Sp. z o.o. on behalf of Polish Neurological Society.
} 


\section{Introduction}

Genetic background of transient ischemic attack (TIA) and ischemic stroke (IS) remains unclear. Substantial genetic and pathophysiological heterogeneity of stroke has been indicated by genome wide association study (GWAS) [1,2]. Little is known about the association of cerebrovascular events with genetic variants of proteins involved in fibrinolysis.

Alpha-2-antiplasmin ( $\alpha 2 \mathrm{AP})$, the main physiological inhibitor of plasmin, has been shown to reduce the efficacy and safety of tissue plasminogen activator (tPA) therapy for IS in mouse models $[3,4]$. $\alpha 2 \mathrm{AP}$ inactivation during tPA treatment improved thrombus dissolution and reduced brain infarction, swelling and hemorrhage. In contrast to the protective effects of $\alpha 2 \mathrm{AP}$ deficiency or inactivation in cerebral ischemia, higher $\alpha 2 \mathrm{AP}$ levels correlated with greater ischemic brain injury and reduced middle cerebral artery thrombus dissolution [4].

Until now, 5 mutations causing congenital $\alpha$ AP deficiency and three polymorphisms, Arg6Trp, Ala26Val and Arg407Lys of unknown clinical significance have been identified [5,6]. The

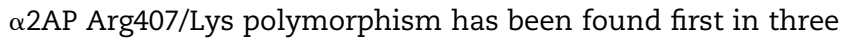
family members with bleeding tendency [6]. In patients with abdominal aortic aneurysm (AAA), Arg407Lys and Arg6Trp polymorphisms were associated with total plasma $\alpha 2$ AP levels that were higher in AAA patients as compared to controls [7]. The AAA occurred less frequently in the 407Lys allele carriers [8]. The $\alpha 2$ AP Arg407Lys polymorphism has been found to have no association with myocardial infarction (MI) risk [9].

We put forward a hypothesis that IS occurs less frequently in the $\alpha 2 \mathrm{AP}$ 407Lys allele carriers. We investigated relationships of the $\alpha 2 A P$ Arg407Lys polymorphism and ischemic cerebrovascular events of unknown origin as well as their neurological outcomes.

\section{Methods}

A total of 165 consecutive adult white patients with a history of cryptogenic IS or TIA aged 70 years or less were referred to the Center for Coagulation Disorders in Cracow, Poland between May 2006 and December 2014 in order to exclude thrombophilia as a potential cause of cerebrovascular events. Exclusion criteria were antiphospholipid syndrome (APS), known malignancy, well-established causes of cerebrovascular events (e.g. documented atrial fibrillation), current anticoagulation, endstage renal disease or liver cirrhosis. The diagnosis of IS was based on clinical symptoms according to the World Health Organization (WHO) definition [10] and brain imaging, usually non-contrast computed tomography (CT). TIA was defined as a brief episode of neurological dysfunction caused by focal brain or retinal ischemia, with clinical symptoms typically lasting less than one hour and without evidence of acute infarction. Patients were recruited at least 3 months after IS or TIA and the neurological status was assessed using the modified Rankin Scale (mRS) without knowledge of the genetic data [11]. If in the meantime the patients with TIA suffered from IS, they were included in the TIA group. Only patients with cerebral ischemia of obscure or unknown origin were eligible for the study. To exclude occult paroxysmal atrial fibrillation, patent foramen ovale, aortic arch atherosclerosis, valvular disorders, atrial fibrillation, and carotid artery atherosclerosis, transthoracic and tranesophageal echocardiography, ultrasound scanning of the carotid arteries and 24-hour Holter monitoring (repeated within the first month) were performed.

The University Ethical Committee approved the study, and patients provided written informed consent in accordance with Declaration of Helsinki.

The clinical data in the acute phase of cerebrovascular events, including the therapy used and neurological deficits, were collected based on medical records.

Thrombophilias, including elevated factor VIII (FVIII), antithrombin (AT) deficiency, protein C (PC) deficiency, protein S (PS) deficiency, factor V G1691A (FV Leiden) and factor II prothrombin G20210A (FII) were assessed as described [12].

Genomic DNA was extracted from whole blood or a buffy coat following the original protocol using the GenEluteTM Blood Genomic DNA Kit (Sigma-Aldrich Co., St. Louis, MO, USA) and stored at $-80^{\circ} \mathrm{C}$ until analysis. The $\alpha 2 A P$ polymorphism Arg407Lys (rs1057335) was determined using TaqMan SNP Genotyping Assay on an ABI PRISM 7900HT Fast Real-Time PCR System (Life Technologies Co., Carlsbad, CA, USA).

\subsection{Control group}

The distribution of the Arg407Lys polymorphisms genotypes in 53 healthy controls of the same ethnical background was: Arg/Arg: 37 (70\%) and Arg/Lys: 16 (30\%), which agrees with a previous report [8].

\subsection{Statistical analysis}

The distribution of the continuous variables was analyzed by the Shapiro-Wilk test. The variables normally distributed were compared with the Student's t test (with correction to unequal variances if appropriate) and presented as mean \pm standard deviation. Variables with non-normal distribution were analyzed by the Mann-Whitney $U$ test and presented as median [interquartile range]. Categorical variables were presented as counts (percentages) and analyzed by the Pearson's $\chi^{2}$ or Fisher's exact tests if appropriate. A $p$-value of $<0.05$ was considered statistically significant. For multiple comparisons omnibus Fisher's exact tests with Sidâc correction was used.

Simple logistic regression models were used to identify significant determinants of excellent outcome (mRS 0-1). Multiple logistic regression model was constructed stepwise backwards among those variables which $p$-value was smaller than 0.2 in a simple model.

\section{Results}

We studied 123 (75\%) patients following IS, including 96 (78\%) thrombolyzed individuals, and 42 (25\%) after TIA (Table 1). Fifty-eight (35\%) patients had at least one type of thrombophilia with the highest prevalence of FVIII $>150 \%$ ( $n=23,14 \%)$ and FV Leiden ( $n=15,9 \%$ ). Most of the patients $(n=144,87 \%)$ were taking low-dose aspirin following cerebrovascular event (Table 1). 
Table 1 - Patient characteristics.

\begin{tabular}{|c|c|c|c|c|c|c|c|c|c|c|}
\hline Variables & $\begin{array}{l}\text { All patients } \\
\quad(n=165)\end{array}$ & $\begin{array}{l}\text { IS patients } \\
(n=123)\end{array}$ & $\begin{array}{l}\text { TIA patients } \\
\quad(n=42)\end{array}$ & $p$-value & $\begin{array}{l}\text { Arg407 } \\
\text { patients } \\
(n=111)\end{array}$ & $\begin{array}{c}\text { 407Lys } \\
\text { patients } \\
(n=54)\end{array}$ & $p$-value & $\begin{array}{c}\text { Thrombolyzed } \\
\text { patients } \\
(n=97)\end{array}$ & $\begin{array}{c}\text { Non-thrombolyzed } \\
\text { patients }(n=68)\end{array}$ & $p$-value \\
\hline Age, years & $45.6 \pm 11.7$ & $45.9 \pm 11.4$ & $44.8 \pm 11.4$ & 0.87 & $45.0 \pm 11.0$ & $47.9 \pm 12.1$ & 0.1 & $46.2 \pm 10.4$ & $45.3 \pm 12.9$ & 0.63 \\
\hline Male, $n(\%)$ & $57(35)$ & $43(35)$ & $14(33)$ & 0.85 & $40(36)$ & $17(31)$ & 0.56 & $35(36)$ & $22(32)$ & 0.62 \\
\hline BMI, $\mathrm{kg} \mathrm{m}^{-2}$ & $26.5(24.4-29.8)$ & $26.5(24.4-30.0)$ & $26.1(23.9-29.8)$ & 0.44 & $26.6(24.4-30.1)$ & $26.1(24.4-29.8)$ & 0.72 & $26.9(24.4-30.6)$ & $25.2(24.3-28.9)$ & $<0.05$ \\
\hline Current smoking, $n(\%)$ & $35(21)$ & $29(24)$ & $6(14)$ & 0.20 & $18(16)$ & $17(32)$ & 0.02 & $22(23)$ & $13(19)$ & 0.58 \\
\hline Family history of stroke & $6(4)$ & $4(3)$ & $2(5)^{\prime}$ & 0.65 & $3(3)$ & $3(6)$ & 0.39 & $3(3)$ & $3(4)$ & 0.69 \\
\hline \multicolumn{11}{|l|}{ Comorbidities, $n$ (\%) } \\
\hline Arterial hypertension & $42(26)$ & $34(28)$ & $8(19)$ & 0.27 & $26(23)$ & $16(30)$ & 0.39 & $25(26)$ & $17(25)$ & 0.91 \\
\hline Hypercholesterolaemia & $48(29)$ & $31(25)$ & $17(41)$ & 0.06 & $31(28)$ & $17(32)$ & 0.64 & $24(25)$ & $24(35)$ & 0.14 \\
\hline Diabetes & $10(6)$ & $8(7)$ & $2(5)$ & 1.0 & $6(5)$ & $4(7)$ & 0.73 & $4(4)$ & $6(9)$ & 0.32 \\
\hline VTE & $7(4)$ & $3(2)$ & $4(10)$ & 0.07 & $4(4)$ & $3(6)$ & 0.68 & $3(3)$ & $4(6)$ & 0.45 \\
\hline Contraceptives or HRT & $13(8)$ & $11(9)$ & $2(5)$ & 0.52 & $11(10)$ & $2(4)$ & 0.23 & $9(9)$ & $4(6)$ & 0.43 \\
\hline Pregnancy & $9(6)$ & $8(7)$ & $1(2)$ & 0.45 & $7(6)$ & $2(4)$ & 0.72 & $5(5)$ & $4(6)$ & 1.0 \\
\hline \multicolumn{11}{|l|}{ Cerebrovascular events } \\
\hline Thrombolysis, $n$ (\%) & $97(58)$ & $96(78)$ & $1(2)^{a}$ & $<0.001$ & $74(67)$ & $23(43)$ & 0.01 & - & - & - \\
\hline Time since the event (months) & $8(6-12)$ & $9(6-13)$ & $7(6-10)$ & 0.06 & - & - & - & - & - & - \\
\hline mRS $0-1$ & $118(72)$ & $82(67)$ & $36(86)$ & 0.006 & $68(61)$ & $50(93)$ & $<0.001$ & $36(37)$ & $50(74)$ & $<0.001$ \\
\hline mRS 2-6 & $47(28)$ & $41(33)$ & $6(14)$ & 0.006 & $43(39)$ & $4(7)$ & $<0.001$ & $61(63)$ & $18(26)$ & $<0.001$ \\
\hline \multicolumn{11}{|l|}{ Thrombophilia, $n$ (\%) } \\
\hline Factor V Leiden & $15(9)$ & $11(9)$ & $4(10)$ & 1.0 & $10(9)$ & $5(9)$ & 1.0 & $6(6)$ & $9(13)$ & 0.12 \\
\hline Prothrombin 20210A & $3(2)$ & $1(1)$ & $2(5)$ & 0.16 & $2(2)$ & $1(2)$ & 1.0 & $1(1)$ & $2(3)$ & 0.57 \\
\hline PC deficiency & $5(3)$ & $5(4)$ & 0 & 0.33 & $4(4)$ & $1(2)$ & 1.0 & $3(3)$ & $2(3)$ & 1.0 \\
\hline PS deficiency & $6(4)$ & $4(3)$ & $2(5)$ & 0.65 & $5(5)$ & $1(2)$ & 0.67 & $3(3)$ & $3(4)$ & 0.69 \\
\hline AT deficiency & $6(3)$ & $5(4)$ & $6(4)$ & 1.0 & $3(3)$ & $3(6)$ & 0.39 & $3(3)$ & $3(4)$ & 0.70 \\
\hline FVIII $>150 \%$ & $23(14)$ & $15(12)$ & $8(19)$ & 0.27 & $17(15)$ & $6(11)$ & 0.46 & $13(13)$ & $10(15)$ & 0.81 \\
\hline Homocysteine $>15 \mu \mathrm{M}$ & $11(7)$ & $9(7)$ & $2(5)$ & 0.73 & $8(7)$ & $3(6)$ & 1.0 & $8(8)$ & $3(4)$ & 0.53 \\
\hline \multicolumn{11}{|l|}{$\alpha 2 \mathrm{AP}$ Arg407Lys genotypes } \\
\hline Arg/Arg & $111(67)$ & $91(74)$ & $20(48)$ & 0.002 & - & - & - & 74 (76) & $37(54)$ & 0.003 \\
\hline Arg/Lys & $49(30)$ & $29(24)$ & $20(48)$ & 0.003 & - & - & - & $21(22)$ & $28(41)$ & 0.007 \\
\hline Lys/Lys & $5(3)$ & $3(2)$ & $2(4)$ & 0.45 & - & - & - & $2(2)$ & $3(4)$ & 0.39 \\
\hline Allele frequency & & & & & - & - & - & & & \\
\hline Arg & 0.82 & 0.86 & 0.71 & 0.003 & - & - & - & 0.87 & 0.75 & $<0.005$ \\
\hline Lys & 0.18 & 0.14 & 0.29 & 0.003 & - & - & - & 0.13 & 0.25 & $<0.005$ \\
\hline
\end{tabular}

${ }^{a}$ During hospitalization due to transient ischemic attack (TIA) the patient experienced stroke and was treated with thrombolysis.

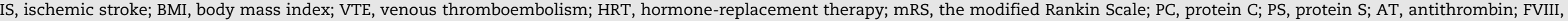
factor VIII; $\alpha 2 \mathrm{AP}$, alpha-2-antyplasim.

Data are shown as mean \pm standard deviation (SD) or a median (interquartile range) or number (percentage). 
The genotype distribution of Arg407Lys polymorphism in the whole group was: Arg/Arg: 111 (67\%), Arg/Lys: 49 (30\%), Lys/ Lys: $5(3 \%)$ and it was in accordance with Hardy-Weinberg equilibrium (HWE) $(p=0.88)$. Allelic frequencies of $\alpha 2 \mathrm{AP}$ Arg407Lys polymorphism were $0.82 / 0.18$. No differences in demographic and clinical characteristics between 407Lys allele carriers and non-carriers were found (Table 1).

No differences in demographic and clinical factors were observed in thrombolyzed and non-thrombolyzed patients, with the exception of BMI, which was higher in the former group $(p<0.05)$. Thrombolysis was performed more often in patients with mRS 2-6 than with mRS 0-1 at the time of acute event ( $p<0.001$ ). Importantly, the 407Lys allele occurred less frequently in patients treated with thrombolysis than in nonthrombolyzed subjects ( $13 \%$ vs. $25 \%, p<0.005$ ) (Table 1 ). Among thrombolyzed patients, more smokers were found in the group with mRS 0-1 compared with subjects with mRS 2-6 ( $32 \%$ vs. $6 \%, p=0.004$; Table 2 ).

Interestingly, the frequency of Arg407Lys genotypes significantly differed among controls, IS and TIA patients. Patients with TIA heterozygous for the 407Lys allele represented a much larger group compared with those with IS and controls whose possessed this genotype (48\% vs. $24 \%$ and $30 \%$; $p=$ 0.015) (Fig. 1A).

In the acute phase of cerebral ischemia mRS score was not associated with the $\alpha 2$ AP Arg407Lys polymorphism or the known thrombophilia (data not shown). Patients with mRS 0-1 and mRS 2-6 after a few months since the event did not differ with regard to demographic and clinical factors, including the known thrombophilia. Only in patients with IS, smoking was associated with mRS 0-1 ( $p=0.01$; Table 2).

In all the patients analyzed together the Arg/Arg genotype was more frequent in those with mRS 2-6 vs. 0-1 points after a few months since the event $(91 \%$ vs. $58 \%, p<0.001$, respectively; Fig. 1B). Similar observation were obtained for IS patients ( $90 \%$ vs. $66 \%, p=0.004$, respectively; Fig. 1B1) and TIA patients ( $100 \%$ vs. $39 \%, p=0.006$; respectively, Fig. 1B2) analyzed separately. Against, the Arg/Lys genotype was found in the majority of patients with mRS 0-1 vs. 2-6 points following the event, in total group (38\% vs. $9 \%, p<0.001$, respectively Fig. 1B), IS patients (31\% vs. $10 \%, p=0.011)$ and TIA patients ( $56 \%$ vs. $0 \%, p=0.012$ ). The Lys/Lys genotype occurred only in a few patients with mRS $0-1$ (in $2 \%$ of the total, $4 \%$ of IS and $4 \%$ of TIA patients) and in no one with mRS 2-6 after 8 (612) months since the event. There were no differences in the frequency of Lys/Lys genotype between patients with mRS 0-1 and mRS 2-6 ( $p=0.15, p=0.22, p=0.59$ for the total group, IS and TIA patients respectively; Fig. 1B, B1 and B2).

The univariate logistic regression model showed that the excellent outcome (mRS 0-1) assessed after 8 (6-12) months since the index cerebral ischemia was predicted by the occurrence of Lys407 allele (OR 7.90; 95\% CI, 2.66-23.46, $p<0.001$ ) but also by the percentage of TIA patients (OR 3.0; $95 \% \mathrm{CI}, 1.17-7.30, p=0.022)$ and the lack of treatment with thrombolysis (OR 2.28; 95\% CI, 1.10-4.76, $p=0.028$; Table 3). In multivariate model, after adjustment for sex, age, smoking status, thrombolyzed treatment and percentage of IS patients, the excellent outcome (mRS 0-1) was predicted only by the Arg407Lys polymorphism (OR 6.18, 95\% CI, 2.01-18.98, $p=0.001 ;$ Table 3).

\section{Discussion}

This study demonstrates that a common $\alpha 2$ AP Arg407Lys polymorphism may have the impact on prognosis in patients with ischemic cerebrovascular events of unknown origin. The patients with Arg/Arg genotype, representing about $67 \%$ of the population, had worse neurological outcomes assessed 8 (612) months since the event compared with those with Arg/Lys genotype, regardless of the thrombolysis.

Little is known about functional consequences of the $\alpha 2 \mathrm{AP}$ Arg407Lys polymorphism. Arg407Lys is positioned in the extended C-terminus of $\alpha 2 \mathrm{AP}$ that binds competitively to the Lys-binding sites of plasmin [8]. It could be speculated that substitution of Arg407 with Lys may affect fibrinolysis through reduction in the efficiency of plasmin- $\alpha 2 \mathrm{AP}$ binding. However, it has been reported that this polymorphism does not influence the cleavage of C-terminal of $\alpha 2 \mathrm{AP}$, plasma clot lysis time, and fibrin clot structure [9]. It has been demonstrated that the presence of 407 Lys allele correlates negatively with the formation of abdominal aortic aneurysm [8] and it does not differentiate patients with MI vs. control subjects [9]. The current study suggests the 407Lys allele affects the course of cerebrovascular ischemia, possibly via mechanisms unrelated to plasmin-mediated fibrinolysis, for instance matrix metalloproteinase expression. This issue requires further investigation.

Importantly, our study shows that carriership of 407Lys allele may predict less serious sequelae of cryptogenic cerebral ischemia after a few months while on low-dose aspirin, though in the acute phase no differences in neurological status related to this allele were observed. Mechanisms underlying this observation remained unknown and these differences cannot be explained by known risk factors for better prognosis such as the use of thrombolysis or younger age.

In the current study neurological outcomes were better in smokers as compared to non-smokers receiving thrombolytic therapy. This phenomenon is in agreement with the previously described smoking thrombolysis-paradox of an improved outcome. The better outcome (modified Rankin Score $=0-2$ ) was found in smokers with IS after intravenous tPA. Moreover, in smokers after thrombolysis for acute MI low mortality risk was observed [13,14]. The polymorphism studied did not confound the impact of smoking on the outcomes of thrombolysis in stroke patients.

Thrombophilia could possibly play a role as a risk factor for ischemic cerebrovascular events development. Recently, it has been shown that inherited deficiencies of natural anticoagulants such as antithrombin, protein $\mathrm{C}$ and protein $\mathrm{S}$ are associated with increased risk of thromboembolic events in Polish population [15]. Any association between thrombophilia and IS or TIA might introduce the limitations to our hypothesis. We did not find none of these, confirming that another factors can be more value regarding to the differences that we observed. Furthermore, our observations were in agreement with the report about the lack of association between the presence of inherited thrombophilias and pathogenic subtypes of ischemic stroke [16]. Also different report showed that inherited thrombophilia mutations like FV Leiden or FII phrotrombin G20210A were not a risk factor for thromboembolic stroke associated with atrial fibrillation [17]. 
Table 2 - Characteristics of patients with mRS 0-1 and mRS 2-6 during follow-up.

\begin{tabular}{|c|c|c|c|c|c|c|c|c|c|c|c|c|}
\hline Variables & $\begin{array}{l}\text { All patients } \\
(n=165)\end{array}$ & $\begin{array}{l}\text { mRS } 0-1 \\
(n=118)\end{array}$ & $\begin{array}{c}\operatorname{mRS} 2-6 \\
(n=47)\end{array}$ & $p$-value & $\begin{array}{l}\text { IS patients } \\
(n=123)\end{array}$ & $\begin{array}{c}\text { mRS 0-1 } \\
(n=82)\end{array}$ & $\begin{array}{c}\text { mRS } 2-6 \\
(n=41)\end{array}$ & $p$-value & $\begin{array}{l}\text { Thrombolyzed } \\
\text { patients }(n=97)\end{array}$ & $\begin{array}{c}\text { mRS 0-1 } \\
(n=63)\end{array}$ & $\begin{array}{c}\text { mRS } 2-6 \\
(n=34)\end{array}$ & $p$-value \\
\hline Age, years & $45.8 \pm 11.4$ & $46 \pm 11.6$ & $45.3 \pm 11.1$ & 0.70 & $45.9 \pm 11.4$ & $46 \pm 12$ & $45.8 \pm 11.04$ & 0.92 & $46.2 \pm 10.4$ & $45.7 \pm 11.2$ & $47 \pm 8.8$ & 0.57 \\
\hline Male, $n(\%)$ & $57(35)$ & $39(33)$ & $18(38)$ & 0.52 & $43(35)$ & $28(34)$ & $15(37)$ & 0.79 & $35(36)$ & $21(33)$ & $14(41)$ & 0.44 \\
\hline BMI, $\mathrm{kg} \mathrm{m}^{-2}$ & $\begin{array}{l}26.5 \\
(24.4-29.8)\end{array}$ & $\begin{array}{l}26.8 \\
(24.3-30.1)\end{array}$ & $\begin{array}{l}26 \\
(24.5-29.4)\end{array}$ & 0.91 & $\begin{array}{l}26.5 \\
(24.4-30)\end{array}$ & $\begin{array}{l}27 \\
(24.4-30.2)\end{array}$ & $\begin{array}{l}26.1 \\
(24.3-28.7)\end{array}$ & 0.48 & $\begin{array}{l}26.9 \\
(24.4-30.6)\end{array}$ & $\begin{array}{l}27.3 \\
(24.3-30.8)\end{array}$ & $\begin{array}{l}26.5 \\
(25.0-29.0)\end{array}$ & 0.38 \\
\hline Current smoking, $n$ (\%) & $35(21)$ & $29(25)$ & $6(13)$ & 0.09 & $29(24)$ & $25(31)$ & $4(10)$ & 0.01 & $22(23)$ & $20(32)$ & $2(6)$ & 0.004 \\
\hline Family history of stroke & $6(4)$ & $5(4)$ & $1(2)$ & 0.68 & $4(4)$ & $3(4)$ & $1(3)$ & 1.0 & $3(3)$ & $2(3)$ & $1(3)$ & 1.0 \\
\hline \multicolumn{13}{|l|}{ Comorbidities, $n$ (\%) } \\
\hline Arterial hypertension & $42(26)$ & $29(25)$ & $13(28)$ & 0.68 & $34(28)$ & $22(27)$ & $12(29)$ & 0.78 & $25(26)$ & $16(25)$ & $9(26)$ & 0.91 \\
\hline Hypercholesterolemia & $48(29)$ & $34(29)$ & $14(30)$ & 0.90 & $31(25)$ & $17(21)$ & $14(34)$ & 0.11 & $24(25)$ & $13(21)$ & $11(32)$ & 0.20 \\
\hline Diabetes & $10(6)$ & $8(7)$ & $2(4)$ & 0.73 & $8(7)$ & $6(7)$ & $2(5)$ & 0.72 & $4(4)$ & $2(3)$ & $2(6)$ & 0.61 \\
\hline VTE & 7 (4) & $6(5)$ & $1(2)$ & 0.67 & $3(2)$ & $2(2)$ & $1(2)$ & 1.0 & $3(3)$ & $2(3)$ & $1(3)$ & 1.0 \\
\hline Contraceptives or HRT & 13 (8) & $8(7)$ & $5(11)$ & 0.52 & $11(9)$ & $7(9)$ & $4(10)$ & 1.0 & $9(9)$ & $5(8)$ & $4(12)$ & 0.72 \\
\hline Pregnancy & $9(6)$ & $5(4)$ & $4(9)$ & 0.28 & $8(7)$ & $4(5)$ & $4(10)$ & 0.44 & $5(5)$ & $2(3)$ & $3(9)$ & 0.34 \\
\hline \multicolumn{13}{|l|}{ Cerebrovascular events } \\
\hline Thrombolysis, $n$ (\%) & $97(59)$ & $63(53)$ & $34(72)$ & 0.03 & $96(78)$ & $63(77)$ & $33(80)$ & 0.64 & & & & \\
\hline $\begin{array}{l}\text { Time since the event } \\
\text { (months) }\end{array}$ & $8(6-12)$ & $8(6-12)$ & $7(6-11)$ & 0.50 & $9(6-13)$ & $9(6-13)$ & $7(6-12)$ & 0.30 & $9(6-12.5)$ & $9(6-13)$ & $8(6-12)$ & 0.72 \\
\hline \multicolumn{13}{|l|}{ Thrombophilia, n (\%) } \\
\hline Factor V Leiden & $15(9)$ & $11(9)$ & $4(9)$ & 1.0 & $11(9)$ & $7(9)$ & $4(10)$ & 1.0 & $6(6)$ & $4(6)$ & $2(6)$ & 1.0 \\
\hline Prothrombin 20210A & $3(2)$ & $3(3)$ & 0 & 0.56 & $1(1)$ & $1(1)$ & 0 & 1.0 & $1(1)$ & $1(2)$ & 0 & 1.0 \\
\hline PC deficiency & $5(3)$ & $3(3)$ & $2(4)$ & 0.62 & $5(4)$ & $3(4)$ & $2(5)$ & 1.0 & $3(3)$ & $2(3)$ & $1(3)$ & 1.0 \\
\hline PS deficiency & 6 (4) & $3(3)$ & $3(6)$ & 0.35 & $4(3)$ & $1(1)$ & $3(7)$ & 0.11 & $3(3)$ & $1(2)$ & $2(6)$ & 0.28 \\
\hline AT deficiency & $6(4)$ & $5(4)$ & $1(2)$ & 0.68 & $5(4)$ & $4(5)$ & $1(2)$ & 0.66 & $3(3)$ & $2(3)$ & $1(3)$ & 1.0 \\
\hline FVIII > 150\% & $23(14)$ & $17(14)$ & $6(13)$ & 0.78 & $15(12)$ & $11(13)$ & $4(10)$ & 0.56 & $13(13)$ & 9 (14) & $4(12)$ & 1.0 \\
\hline Homocysteine $>15 \mu \mathrm{M}$ & $11(7)$ & $7(6)$ & $4(9)$ & 0.51 & $9(7)$ & $6(7)$ & $3(7)$ & 1.0 & $8(8)$ & $5(8)$ & $3(9)$ & 1.0 \\
\hline
\end{tabular}



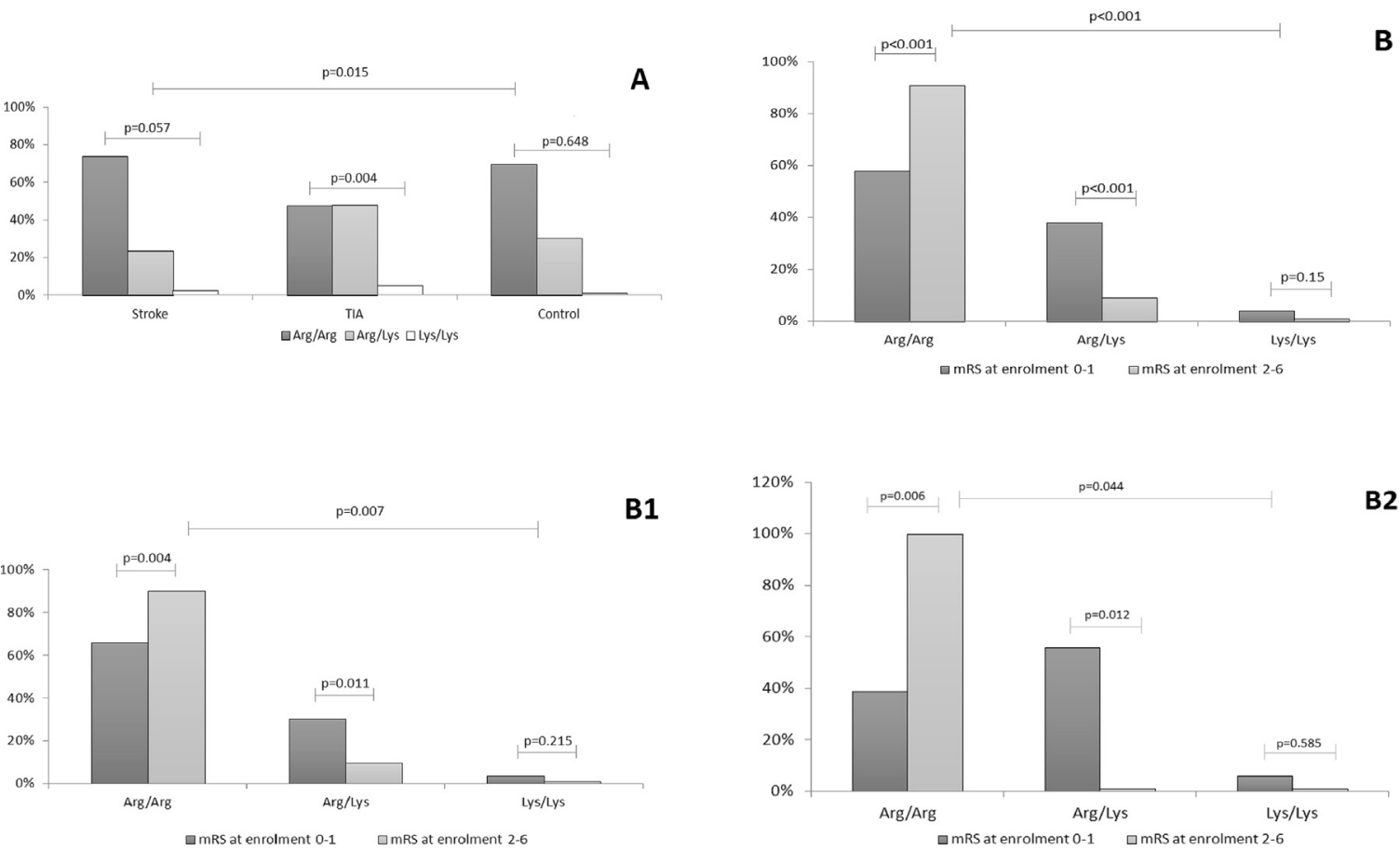

Fig. 1 - The distribution of $\alpha 2$ AP Arg407Lys genotypes among patients experienced cryptogenic ischemic stroke (IS) vs. transient ischemic attack (TIA) and controls (panel A). The Fisher Exact Test was used for statistical analysis. $p$-value $<0.05$ was considered statistically significant. For multiple comparisons the Omnibus Fisher Exact Test was used. After Ŝidâc correction the significance of $p$-value was considered $<0.017$. The distribution of $\alpha 2 \mathrm{AP}$ Arg407Lys genotypes among total patients (panel B), IS patients (panel B1) and TIA patients (panel B2), with the neurological outcomes assessed at 8 (6-12) months after ischemic stroke (IS) defined by the modified Rankin Scale (mRS) as the excellent recovery (mRS score $0-1)$ and poor outcome (mRS score 2-6). Statistical analysis was assessed using Fisher Exact Test. $p$-value $<0.05$ was considered statistically significant.

\begin{tabular}{|c|c|c|c|}
\hline \multirow[t]{2}{*}{ Variables } & \multicolumn{3}{|c|}{ Univariate regression model } \\
\hline & OR & $95 \% \mathrm{CI}$ & $p$-value \\
\hline 407Lys allele & 7.90 & $2.66-23.46$ & $<0.001$ \\
\hline Arg407 allele & 0.13 & $0.04-0.38$ & $<0.001$ \\
\hline IS & 0.33 & $0.13-0.86$ & 0.022 \\
\hline TIA & 3.00 & $1.17-7.30$ & 0.022 \\
\hline Thrombolysis & 0.44 & $0.21-0.91$ & 0.028 \\
\hline Non-thrombolysis & 2.28 & $1.10-4.76$ & 0.028 \\
\hline \multicolumn{4}{|c|}{ Multivariate regression model } \\
\hline 407Lys allele & 6.18 & $2.01-18.97$ & 0.0015 \\
\hline
\end{tabular}

Our study has several limitations. The number of the patients studied was relatively low and our findings require validation in another larger population. We cannot exclude that a subset of our patients did have paroxysmal AF as a causal factor for stroke based on our post stroke diagnostic work-up, but this factor cannot significantly affect our major findings. The diagnosis of cryptogenic cerebrovascular events is always challenging and evolves with rising numbers of their identified causes. Finally, in vitro studies are needed to translate our observations onto a molecular level.

\section{Conclusions}

In conclusion, we have shown that possession of a lysine at position 407 in $\alpha 2 \mathrm{AP}$ is less common among patients with IS. Moreover, 407Lys allele is associated with better outcomes after IS or TIA events. Although our findings should be replicated in other studies, the current report provides additional evidence for the genetically regulated role of $\alpha 2 \mathrm{AP}$, the inhibitor attracting rapidly growing attention as a potential new therapeutic agent $[18,19]$, in cerebral ischemia and its clinical outcomes. Therefore, not only stroke specialists, internists and general practitioners [20] but also geneticists need to cooperate for improving the prognosis and reducing stroke burden worldwide.

\section{Funding}

This study was supported by Jagiellonian University Medical College (K/ZDS/002936 to A.U.).

\section{Conflicts of interest}

None declared. 


\section{R E F E R E N C E S}

[1] Dichgans M. Genetics of ischaemic stroke. Lancet Neurol 2007;6(2):149-61.

[2] Traylor M, Farrall M, Holliday EG, Sudlow C, Hopewell JC, Chenget Y, et al. Genetic risk factors for ischaemic stroke and its subtypes (the METASTROKE Collaboration): a metaanalysis of genome-wide association studies. Lancet Neurol 2012;11(11):951-62.

[3] Carpenter SL, Mathew P. Alpha2-antiplasmin and its deficiency: fibrinolysis out of balance. Haemophilia 2008;14 (6):1250-4.

[4] Reed GL, Houng AK, Wang D. Microvascular thrombosis, fibrinolysis, ischemic injury and death after cerebral thromboembolism are affected by levels of circulating a2-antiplasmin. Arterioscler Thromb Vasc Biol 2014;37 (11):2586-93.

[5] Favier R, Aoki N, de Moerloose P. Congenital a2-plasmin inhibitor deficiencies: a review. Br J Haematol 2001;114(1): 4-10.

[6] Lind B, Thorsen S. A novel missense mutation in the human plasmin inhibitor (alpha2-antiplasmin) gene associated with a bleeding tendency. Br J Haematol 1999;107 (2):317-22.

[7] Zhong J, Bridge K, Ariens R, Scott DJ. Alpha-2-antiplasmin activity is increased in patients with AAA. SARS abstracts. Br J Surg 2015;103(9):6-49.

[8] Bridge K, Macrae F, Bailey MA, Johnson A, Philippou H, Scott DJ, et al. The alpha-2-antiplasmin Arg407Lys polymorphism is associated with abdominal aortic aneurysm. Thromb Res 2014;134(3):723-8.

[9] de Willige SU, Miedzak M, Carter AM, Lisman T, Rosendaal PJ, Grant PJ, et al. Proteolytic and genetic variation of the alpha-2-antiplasmin C-terminus in myocardial infarction. Blood 2011;117(24):6694-701.

[10] Global status report on noncommunicable diseases. World Health Organization web site. http://www.who.int/ nmh/publications/ncd-status-report-2014/en/ [accessed 2014].

[11] van Swieten JC, Koudstaal PJ, Visser MC, Schouten HJ, van Gijn J. Interobserver agreement for the assessment of handicap in stroke patients. Stroke 1988;19(5):604-7.

[12] Kościelniak B, Wypasek E, Undas A. Determinants of elevated levels of natural anitcoagulants in healthy subject. Adv Clin Exp Med 2015;24(5):791-800.

[13] Kufner A, Nolte CH, Galinovic I, Brunecker P, Kufner GM, Endres $\mathrm{M}$, et al. Smoking-thrombolysis paradox: recanalization and reperfusion rates after intravenous tissue plasminogen activator in smokers with ischemic stroke. Stroke 2013;44(2):407-13.

[14] Angeja BG, Kermgard S, Chen MS, McKay M, Murphy SA, Antman EM, et al. The smoker's paradox: insights from the angiographic substudies of the TIMI trials. J Thromb Thrombolysis 2002;13(3):133-9.

[15] Wypasek E, Corral J, Alhenc Gelas M, Sydor W, Iwaniec T, Celińska Lowenhoff M, et al. Genetic characterization of antithrombin, protein $\mathrm{C}$, and protein $\mathrm{S}$ deficiencies in Polish patients. Pol Arch Intern Med 2017;127(7-8):512-23.

[16] Hankey GJ, Eikelboom JW, van Bockxmeer FM, Lofthouse E, Staples N, Baker RI. Inherited thrombophilia in ischemic stroke and its pathogenic subtypes. Stroke 2001;32(8): 1793-9.

[17] Berge E, Haug KB, Sandset EC, Haugbro KK, Turkovic M, Sandset PM. The factor V Leiden, prothrombin gene 20210GA, methylenetetrahydrofolate reductase 677CT and platelet glycoprotein IIIa 1565TC mutations in patients with acute ischemic stroke and atrial fibrillation. Stroke 2007;38 (3):1069-71.

[18] Reed GL, Houng AK, Singh S, Wang D. $\alpha 2$-Antiplasmin: new insights and opportunities for ischemic stroke. Semin Thromb Hemost 2017;43(2):191-9.

[19] Urano T, Suzuki Y. Thrombolytic therapy targeting alpha 2-antiplasmin. Circulation 2017;135(11):1021-3.

[20] Niewada M, Członkowska A. Prevention of ischemic stroke in clinical practice: a role of internists and general practitioners. Pol Arch Intern Med 2014;124(10):540-8. 